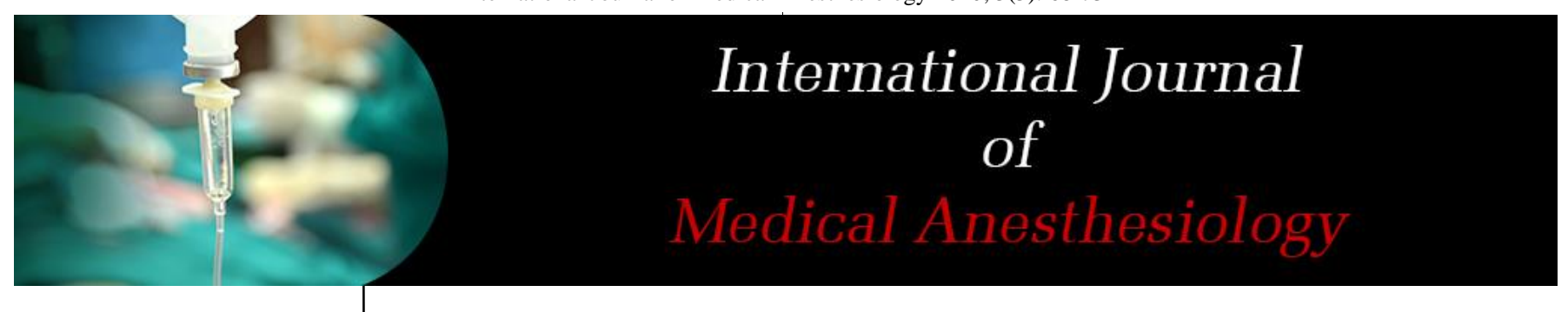

E-ISSN: 2664-3774

P-ISSN: 2664-3766

Www.anesthesiologypaper.com

IJMA 2020; 3(3): 68-73

Received: 04-06-2020

Accepted: 29-06-2020

Dr. Ranjini Basavaraj Nataraj Senior Resident, Department of Anaesthesiology, Subbaiah Institute of Medical Sciences, Shimoga, Karnataka, India

Dr. Shankaranarayana $P$ Professor, Department of Anaesthesiology, Yenepoya Medical College, Mangalore, Karnataka, India

Dr. Ganapati $P$

Professor, Department of Anaesthesiology, KVG Medical College, Sullia, Karnataka, India
Corresponding Author:

Dr. Ranjini Basavaraj Nataraj Senior Resident, Department of Anaesthesiology, Subbaiah Institute of Medical Sciences, Shimoga, Karnataka, India

\section{A study on efficacy of isobaric Levobupivacaine and Fentanyl with Isobaric Ropivacaine and Fentanyl in patients undergoing TURP at a tertiary care hospital}

\author{
Dr. Ranjini Basavaraj Nataraj, Dr. Shankaranarayana $P$ and Dr. \\ Ganapati P
}

DOI: https://doi.org/10.33545/26643766.2020.v3.i3b.150

\begin{abstract}
For decades, lignocaine had been the local anaesthetic of choice for spinal anaesthesia. Its advantages are rapid onset of action and good motor block manifested as good muscle relaxation. Its use was limited by its short duration of action and has been implicated in transient neurologic symptoms and cauda equina syndrome following intrathecal injection. Bupivacaine is three to four times more potent than lignocaine and has longer duration of action. The study includes 30 males in each group (group $\mathrm{R}$ and group L) satisfying the inclusion criteria. Group R: $2.6 \mathrm{cc}$ of $0.75 \%$ isobaric ropivacaine (19.5mg) with $0.4 \mathrm{cc}$ of fentanyl (20 microgram). Group L: $2.6 \mathrm{cc}$ of $0.5 \%$ isobaric levobupivacaine $(13 \mathrm{mg})$ with $0.4 \mathrm{cc}$ of fentanyl (20 microgram). This study reveals that the intrathecal $2.6 \mathrm{ml}$ of $0.75 \%$ isobaric ropivacaine with fentanyl $20 \mu \mathrm{g}$ provides adequate anaesthesia for TURP cases. Ropivacaine achieves a longer duration of sensory and motor blockade as compared with $0.5 \%$ isobaric levobupivacaine. With the quality and duration of block achieved with ropivacaine, it can be justified to use it for TURP cases. In conclusion, $0.75 \%$ isobaric ropivacaine with fentanyl prolongs sensory and motor block durations providing adequate anaesthesia for patients undergoing TURP under SAB and post operative analgesia compared to $0.5 \%$ levobupivacaine without causing any difference in significant side-effects. Hence, ropivacaine with fentanyl in spinal anaesthesia for TURP cases is a better alternative compared to levobupivacaine with fentanyl.
\end{abstract}

Keywords: TURP, Isobaric Levobupivacaine, Fentanyl with Isobaric Ropivacaine

\section{Introduction}

Neuraxial anaesthesia and particularly intrathecal anaesthesia is an important part of clinical anaesthesiology. Coinciding with the developments in other fields of medicine, regional anaesthesia too, has undergone major developments both in the techniques and drug availability. When questions about the cardiotoxity of bupivacaine were raised initially by Dr. Albright in 1979, particularly when it had been in widespread clinical use for a long period without reported ill effects, the search for an alternate local anaesthetic with little or no adverse effects became inevitable.

One among those new series of local anaesthetic molecules was ropivacaine and ever since then, there have been numerous studies to evaluate the use of this new local anaesthetic molecule with regard to its effectiveness as local anaesthetic, potency, safety profile when compared to established drugs.

Lower urinary tract symptoms suggestive of Benign Prostatic Hyperplasia (BPH) are frequently encountered in ageing men. Over the age of 40, about one quarter of men suffer from BPH. There are three treatment options for BPH namely watchful waiting, pharmacological interventions and surgery (minimally invasive).

Surgery is recommended for patients who are moderately to severely bothered by their BPH and refractory to medical treatment. Transurethral resection of prostate (TURP) is one of the most common procedures performed in elderly men. Spinal anaesthesia (SA) or Subarachnoid block (SAB) is the most frequently used anaesthesia technique for TURP as it is the fastest, most predictable and reliable form of regional anaesthesia ${ }^{[1]}$.

Under SAB, the signs and symptoms of water intoxication, fluid overload, TURP syndrome and bladder perforation can be recognized early as the patient is awake. 
Spinal anaesthesia is a safe, reliable and inexpensive technique with the advantage of providing surgical anaesthesia and also extended pain relief in post operative period. It is also an effective treatment for acute operative pain and blunts autonomic, somatic and endocrine responses.

Spinal anaesthesia with cocaine was initially produced inadvertently by $\mathrm{J}$ Leonard Corning in 1885, and first used deliberately by August Bier in 1898.

For decades, lignocaine had been the local anaesthetic of choice for spinal anaesthesia. Its advantages are rapid onset of action and good motor block manifested as good muscle relaxation. Its use was limited by its short duration of action and has been implicated in transient neurologic symptoms and cauda equina syndrome following intrathecal injection. Bupivacaine is three to four times more potent than lignocaine and has longer duration of action. Hyperbaric bupivacaine $(0.5 \%)$ is more commonly used for spinal anaesthesia for TURP. Bupivacaine, though long acting has increased the incidence of fatal cardiac toxicity after accidental intravascular injection, because of narrow cardiovascular collapse/central nervous system toxicity ratio (cc/cns). Bupivacaine is available as a racemic mixture of its enantiomers, dextroenantiomer and s-enantiomer. It has been found that dextro-enantiomer is the cause for cardiotoxicity. Levobupivacaine is an s-enantiomer of bupivacaine, and hence emerged as a safer alternative to bupivacaine for regional anaesthesia than its racemic parent in the recent years ${ }^{[2]}$.

In 2009, Ropivacaine a new amide-type long-acting, local anaesthetic and analgesic was introduced in India, though it was being used in other parts of the world since early 1990s. Ropivacaine has similar efficacy but an enhanced safety profile when compared to bupivacaine, a major advantage in regional anaesthesia. Ropivacaine has been recently introduced in India and not many studies have been done in India regarding the use of ropivacaine for spinal anaesthesia ${ }^{[3]}$. Levobupivacaine has similar pharmacodynamic properties of racemic bupivacaine and is documented to be less cardiotoxic and less neurotoxic in cases of accidental intravascular injection and has shorter duration of motor block than racemic bupivacaine.

Protein binding of levobupivacaine (97\%) is more than that of racemic bupivacaine (95\%). There is less free drug circulating in the plasma and acting on other tissues to cause adverse effects and toxicity. Studies have shown that while volumes of distribution and overall clearance of the two drugs are comparable, the clearance of unbound fraction of levobupivacaine is higher.

Levobupivacaine demonstrated lesser affinity and strength of inhibition of cardiac sodium channels in vitro animal tissue experiment studies. It was also less potent in blocking cloned human heart potassium and sodium channels. Experiments in anaesthetized rats receiving arrhythmogenic intravenous levobupivacaine or dextrobupivacaine showed a less rapid blockage of the cell firing in the nucleus tractus solitarius after levobupivacaine than after dextrobupivacaine. Hence potential for cardiovascular and CNS toxicity is lower with levobupivacaine ${ }^{[4]}$.

Though the duration of action of levobupivacaine and ropivacaine is prolonged, it will not produce prolonged postoperative analgesia. Uncontrolled post-operative pain may produce a range of detrimental acute and chronic effects. For this reason there has been in recent years, an increasing interest in the relief of post operative pain by technique using local anaesthestic agents with adjuvant for spinal anaesthesia. Neuraxial adjuvants such as lipophilic opioids (fentanyl), are increasingly being given intrathecally as adjuvant to local anaesthetics to enhance sensory block which improves perioperative analgesia and intensify motor block without increasing sympathetic blockade, prolonging motor recovery and discharge time, and also to minimize the local anaesthetic dose, particularly in high-risk patients and in ambulatory procedures ${ }^{[5]}$.

\section{Methodology}

Preanaesthetic check up was done one day prior to the surgery or earlier whenever required. Patients were evaluated for co-existing systemic diseases and relevant laboratory investigations were reviewed/requested. The procedure of SAB and VAS score was explained to the patient in their own understandable language and written informed consent was obtained.

A total of 60 patients aged between 40 and 80 years with ASA physical status I-III who were scheduled for elective TURP were enrolled in this prospective, randomized comparative study included.

Selected patients were randomly allocated to 2 groups of 30 each by lottery method, prepared by another anaesthetist outside the operating room, namely:

Group R: $2.6 \mathrm{cc}$ of $0.75 \%$ isobaric ropivacaine $(19.5 \mathrm{mg})$ with $0.4 \mathrm{cc}$ of fentanyl (20 microgram).

Group L: 2.6 cc of $0.5 \%$ isobaric levobupivacaine (13 mg) with $0.4 \mathrm{cc}$ of fentanyl (20 microgram).

One day prior to surgery all the patients underwent preanaesthetic check-up and were explained about visual analogue scale (VAS) and were pre-medicated with tab. alprazolam $0.5 \mathrm{mg}$ HS orally.

Before being shifted to operation room, patients were secured with an intravenous (IV) line with $18 \mathrm{G} \mathrm{IV} \mathrm{cannula}$ in the dorsum of hand and preloaded with $10 \mathrm{ml} / \mathrm{kg} /$ hour of ringer lactate over 20 minutes before shifting to operation theatre.

\section{Preparation of Operation room (OR)}

Anaesthesia work station was checked and prepared. Appropriate size endotracheal tubes, working laryngoscope with medium and large size blades, stylet and working suction apparatus were kept ready. Emergency drug tray containing atropine and ephedrine were also kept ready before the procedure.

\section{Procedure}

In the operation room, IV infusion of normal saline at $4 \mathrm{ml} / \mathrm{kg} / \mathrm{hr}$ was started using a dosiflow. All fluids transfused was at room temperature. Patients were monitored with standard anaesthetic monitoring techniques using noninvasive blood pressure, peripheral oxygen saturation and electrocardiography evaluations. The baseline blood pressure, mean arterial pressure, heart rate and oxygen saturation were noted.

With the patient in lateral decubitus position, spinal anaesthesia was performed under strict aseptic conditions and after local infiltration of the skin with $1 \%$ lidocaine. Using 23G Quincke's babcock needle with midline 
approach at L4-L5/L3-L4, the subarachnoid space was entered (determined by palpation of bony landmarks) with bevel pointing cephalad.

Drug was injected slowly (over 15 seconds) without Barbotage technique and after noting the free flow of cerebrospinal fluid. The patient was turned supine immediately after the injection and put in neutral position. All patients were covered with blanket and received oxygen by nasal prongs at $2-3 \mathrm{~L} / \mathrm{min}$. Table tilt was not allowed before ascertaining the sensory block up to T12. A head down tilt was given if maximum sensory level of T10 was not attained within $5 \mathrm{~min}$ after $\mathrm{SAB}$. On confirmation of sensory level of more than T10, patients were placed in lithotomy position. In the event of inadequate spinal block (defined as pain severe enough to interfere with surgical procedure), rescue analgesia was planned with titrated doses of fentanyl followed by general anaesthesia. In case of failure of spinal anaesthesia, it was planned to exclude the patients from the study and convert the case into general anaesthesia (GA was planned with mask induction using $\mathrm{O}_{2}$ and $\mathrm{N}_{2} 0$ 1:1 with titrated doses of propofol. Appropriate size LMA would be placed and maintained on spontaneous ventilation and isoflurane. In our study, no case was converted to GA). Thereafter, hemodynamic changes, which include pulse rate, systolic blood pressure, diastolic blood pressure, MAP, $\mathrm{SpO}_{2}$ were recorded every 2 minutes for the first twenty minutes, and then every 5 minutes for the next thirty minutes and then every 10 minutes thereafter till the end of surgery. Bradycardia defined as the pulse rate of less than 50 beats $/ \mathrm{min}$ was treated with Inj. atropine $0.6 \mathrm{mg}$ IV. Hypotension defined as the decrease in mean arterial pressure less than $60 \mathrm{mmHg}$ or systolic blood pressure less than $20 \%$ from baseline was treated with incremental boluses of Inj. ephedrine $6 \mathrm{mg}$ IV as and when required.

\section{Results}

Table 1: Time of onset of sensory blockade (in minutes) and intergroup comparison

\begin{tabular}{|c|c|c|c|c|c|c|c|}
\hline Group & N & Mean & SD & Min & Max & T & P \\
\hline & & & & & & Value & Value \\
\hline Ropivacaine and & 30 & 1.5 & 0.70 & 1 & 4 & 12.9795 & $<0.0001$ \\
\hline Fentanyl group & & & & & & & \\
\hline Levobupivacaine & 30 & 4.53 & 1.07 & 3 & 6 & & \\
\hline And fentanyl & & & & & & & \\
\hline Group & & & & & & & \\
\hline
\end{tabular}

The above table shows the mean time of onset of sensory blockade in ropivacaine $0.75 \%$ group is $1.5 \pm 0.70 \mathrm{mins}$ and in levobupivacaine $0.5 \%$ group is $4.53 \pm 1.07 \mathrm{mins}$. There is a statistically significant difference between the two groups regarding the onset of sensory blockade ( $p$ value $<0.0001$ ), with the sensory onset being faster in ropivacaine $0.75 \%$ group.

Table 2: Time of onset of sensory blockade to 10 (in minutes) and intergroup comparison

\begin{tabular}{|c|c|c|c|c|c|c|c|}
\hline Group & $\mathbf{N}$ & Mean & SD & Min & Max & T value & P value \\
\hline Ropivacaine and & 30 & 3.32 & 1.23 & 3 & 6 & & \\
\hline Fentanyl group & & & & & & 11.876 & $<0.0001$ \\
\hline Levobupivacaine & 30 & 7.64 & 1.87 & 6 & 12 & & \\
\hline And fentanyl & & & & & & & \\
\hline Group & & & & & & & \\
\hline
\end{tabular}

The above table shows the mean time of onset of sensory blockade to $\mathrm{T} 10$ in ropivacaine $0.75 \%$ group is $3.32 \pm$ $1.23 \mathrm{mins}$ and in levobupivacaine $0.5 \%$ group is $7.64 \pm$ 1.87 mins. There is a statistically significant difference between the two groups regarding the onset of sensory blockade to T10 (p value $<0.0001$ ), with the sensory onset to $\mathrm{T} 10$ being faster in ropivacaine $0.75 \%$ group.

Table 3: Time to reach maximum level of sensory blockade in minutes and intergroup comparison

\begin{tabular}{|c|c|c|c|c|c|c|c|}
\hline Group & $\mathbf{N}$ & Mean & SD & Min & Max & T value & P value \\
\hline Ropivacaine and & 30 & 4.43 & 1.13 & 3 & 6 & & \\
\hline Fentanyl group & & & & & & & \\
\hline Levobupivacaine & 30 & 9.03 & 1.99 & 5 & 13 & 11.0097 & $<0.0001$ \\
\hline And fentanyl & & & & & & & \\
\hline Group & & & & & & & \\
\hline
\end{tabular}

The above table shows the mean time to reach the maximum sensory blockade, which is $4.43 \pm 1.13$ mins in ropivacaine $0.75 \%$ group and $9.03 \pm 1.99$ mins in levobupivacaine $0.5 \%$ group. There is a statistically significant difference between the two groups ( $p$ value $<0.0001$ ).

Table 4: Time for 2 segment regression of sensory blockade (in minutes) and intergroup comparison

\begin{tabular}{|c|c|c|c|c|c|c|c|}
\hline Group & N & Mean & SD & Min & Max & T value & P value \\
\hline Ropivacaine and & 30 & 84 & 13.92 & 55 & 110 & & \\
\hline Fentanyl group & & & & & & & \\
\hline Levobupivacaine & 30 & 64 & 13.92 & 35 & 90 & 5.5646 & $<0.0001$ \\
\hline And fentanyl & & & & & & & \\
\hline Group & & & & & & & \\
\hline
\end{tabular}

The mean time taken for 2 segment sensory regression is 84 \pm 13.92 mins in ropivacaine $0.75 \%$ group and $64 \pm 13.92 \mathrm{mins}$ in levobupivacaine $0.5 \%$ group. There is a statistically highly significant difference between the groups ( $p$ value $<0.0001$ ) with faster regression of sensory block in levobupivacaine $0.5 \%$ group.

Table 5: Duration of sensory blockade (in minutes) and intergroup comparison

\begin{tabular}{|c|c|c|c|c|c|c|c|}
\hline Group & N & Mean & SD & Min & Max & T value & P value \\
\hline Ropivacaine and & 30 & 177.5 & 50.44 & 100 & 255 & & \\
\hline Fentanyl group & & & & & & & \\
\hline Levobupivacaine & 30 & 110.83 & 29.36 & 65 & 160 & 6.2569 & $<0.0001$ \\
\hline And fentanyl & & & & & & & \\
\hline Group & & & & & & & \\
\hline
\end{tabular}

The mean duration of sensory blockade is $177.5 \pm 50.44$ mins in ropivacaine $0.75 \%$ group and $110.83 \pm 29.36$ mins in levobupivacaine $0.5 \%$ group. There is a statistically highly significant difference between the groups ( $p$ value $<0.0001$ ) with longer duration of sensory blockade in ropivacaine $0.75 \%$ group.

Table 6: Time of onset of motor blockade (in minutes) and intergroup comparison

\begin{tabular}{|c|c|c|c|c|c|c|c|}
\hline Group & $\mathbf{N}$ & Mean & SD & Min & Max & T value & P value \\
\hline Ropivacaine and & 30 & 3.56 & 1.13 & 2 & 5 & & \\
\hline Fentanyl group & & & & & & & \\
\hline Levobupivacaine & 30 & 7.26 & 1.41 & 5 & 11 & 11.2156 & $<0.0001$ \\
\hline And fentanyl & & & & & & & \\
\hline Group & & & & & & & \\
\hline
\end{tabular}


The mean time taken for the onset of motor blockade is 3.56 \pm 1.13 mins in Ropivacaine $0.75 \%$ group and $7.26 \pm 1.41 \mathrm{mins}$ in levobupivacaine $0.5 \%$ group. There is a statistically significant difference between the groups ( $p$ value $<0.0001$ ).

Table 7: Duration of motor blockade (in minutes) and intergroup comparison

\begin{tabular}{|c|c|c|c|c|c|c|c|}
\hline Group & N & Mean & SD & Min & Max & T value & P value \\
\hline Ropivacaine and & 30 & 255.16 & 29.05 & 200 & 305 & & \\
\hline Fentanyl group & & & & & & & \\
\hline Levobupivacaine & 30 & 202.5 & 23.25 & 160 & 245 & 7.7518 & $<0.0001$ \\
\hline And fentanyl & & & & & & & \\
\hline Group & & & & & & & \\
\hline
\end{tabular}

The mean duration of motor blockade is $255.16 \pm 29.05 \mathrm{mins}$ in ropivacaine $0.75 \%$ group and $202.5 \pm 23.25 \mathrm{mins}$ in levobupivacaine $0.5 \%$ group. There is a statistically highly significant difference between the two groups ( $p$ value $<0.0001)$.

Table 8: Regression to S1

\begin{tabular}{|c|c|c|c|c|c|c|c|}
\hline Group & N & Mean & SD & Min & Max & T value & P value \\
\hline Ropivacaine and & 30 & 329.83 & 20.90 & 280 & 365 & & \\
\hline Fentanyl group & & & & & & & \\
\hline Levobupivacaine & 30 & 273 & 19.10 & 230 & 320 & 10.9940 & $<0.0001$ \\
\hline And fentanyl & & & & & & & \\
\hline Group & & & & & & & \\
\hline
\end{tabular}

The mean time taken for the level to regress to $\mathrm{S} 1$ is
$329.83 \pm 20.90 \mathrm{mins}$ in ropivacaine $0.75 \%$ group and $273 \pm$ $9.10 \mathrm{mins}$ in levobupivacaine $0.5 \%$ group. There is statistically highly significant difference between the groups (p value $<0.0001$ ).

Table 9: Maximum Motor Block

\begin{tabular}{|c|c|c|c|c|c|c|c|}
\hline Group & N & Mean & SD & Min & Max & T value & P value \\
\hline Ropivacaine and & 30 & 3 & 0 & 3 & 3 & & \\
\hline Fentanyl group & & & & & & & \\
\hline Levobupivacaine & 30 & 3 & 0 & 3 & 3 & $\mathrm{Na}$ & $\mathrm{Na}$ \\
\hline And fentanyl & & & & & & & \\
\hline Group & & & & & & & \\
\hline
\end{tabular}

The maximum motor bock attained in both the groups was MBS 3.

Table 10: Time to attain maximum motor blockade

\begin{tabular}{|c|c|c|c|c|c|c|c|}
\hline Group & $\mathbf{N}$ & Mean & SD & Min & Max & T value & P value \\
\hline Ropivacaine and & 30 & 6.43 & 1.13 & 5 & 8 & & \\
\hline Fentanyl group & & & & & & & \\
\hline Levobupivacaine & 30 & 12.46 & 2.08 & 10 & 16 & 13.9526 & $<0.0001$ \\
\hline And fentanyl & & & & & & & \\
\hline Group & & & & & & & \\
\hline
\end{tabular}

The mean time taken for attaining maximum motor blockade is $6.43 \pm 1.13$ mins in ropivacaine $0.75 \%$ group and $12.46 \pm 2.08$ mins in levobupivacaine $0.5 \%$ group. There is a statistically highly significant difference between the groups ( $\mathrm{p}$ value $<0.0001$ )

Table 11: Observed side-effects in both the groups

\begin{tabular}{|c|c|c|c|c|}
\hline SI no. & Side effects & Ropivacaine and & Levobupivacaine & P value \\
\hline & & Fentanyl group. & And fentanyl & Group. No. (\%) \\
\hline & & No. $(\boldsymbol{\%})$ & $7(23.33 \%)$ & 0.5675 \\
\hline 1 & Hypotension & $10(33.33 \%)$ & $4(13.33 \%)$ & 0.6707 \\
\hline 2 & Nausea & $2(6.66 \%)$ & $3(10 \%)$ & 0.7065 \\
\hline 3 & Shivering & $5(16.66 \%)$ & $2(6.66 \%)$ & 1 \\
\hline 4 & Bradycardia & $2(6.66 \%)$ & $1(3.33 \%)$ & - \\
\hline 5 & Pruritis & $0(0 \%)$ & $30(100 \%)$ & \\
\hline \multicolumn{2}{|r|}{ Total no. Of patients } & $30(100 \%)$ & & \\
\hline
\end{tabular}

Total 17 patients suffered hypotension intraoperatively of which 10 belonged to group $\mathrm{R}$ and 7 to Group L. Bradycardia was seen in total 4 patients, 2 in each Group. Nausea was seen in 6 patients of which 2 belonged to Group $\mathrm{R}$ and 4 to Group L. Shivering was seen in 8 patients of which 5 belonged to Group R and 3 belonged to Group L. Pruritus was seen in only one patient in Group L. These data were statistically insignificant.

\section{Discussion}

Ropivacaine is a new long acting local anaesthetic drug belonging to the amino amide group. Though it was synthesized by Ekenstam in 1957 and belongs to the same group as that of bupivacaine and mepivacaine (pipecoloxylidides local anaesthetics) ropivacaine was introduced to clinical practice in 1996.

Historically, bupivacaine was used as it had a longer duration of action, but subsequently it was found that "propyl derivatives" of pipecoloxylidides were less toxic than ,butyl derivatives ${ }^{\text {ee }}$ (bupivacaine). Thus, ropivacaine was developed after bupivacaine was noted to be associated with significant number of cardiac arrests. Despite being in the market for close to three decades internationally, it was only introduced into the Indian market very recently.

Intrathecal administration of fentanyl produces selective spinal analgesia by acting on opioid receptors at substantia gelatinosa of dorsal horn of the spinal cord. Opioids and local anaesthetics exert their antinociceptive effect in the spinal cord by different mechanisms. The $\mu$ agonist fentanyl, exerts its action by opening $\mathrm{K}^{+}$channels and reducing $\mathrm{Ca}^{++}$influx, resulting in inhibition of transmitter release. The $\mu$ agonists also have a direct postsynaptic effect, causing hyper-polarization and a reduction in neuronal activity.

Local anaesthetics may also interfere with synaptic transmission by presynaptic inhibition of $\mathrm{Ca}^{++}$channels in addition to their effects on nerve conduction.

Intrathecal and epidural narcotics seem to modulate pain primarily at the spinal cord rather than in the brain, as do IV narcotics. The blood and CSF concentrations of fentanyl following epidural administration depend more on spinal cord absorption. The site of action in the spinal cord may provide analgesia and less sedation, confusion and nausea which are often associated with intravenous narcotics.

The mean time of onset of sensory blockade and time to reach T10 as assessed by loss of pain sensation in our study 
was $1.50 .70,4.321 .23$ minutes respectively in group $\mathrm{R}$ and 4.561 .07 and 8.641 .87 in group L ( $p$ value $<0.0001$ which is highly significant) which is comparable with that of Wahedi et al. who reported a mean onset time of 2 minutes and Gupta $\mathrm{R}$ et al. who reported onset of sensory blockade to $\mathrm{T} 10$ in $3.5 \pm 1.2 \mathrm{mins}$ in group R. But Esmaoglu et al., reported time taken for onset of sensory blockade in levobupivacaine group to be $2.2 \pm 0.7 \mathrm{~min}$ which is shorter compared to our study and time to reach T10 was $7.5 \pm 2.7$ min comparable with our study. The time of onset of sensory blockade and time to reach T10 was significantly different statistically between both the study groups.

A T10 sensory level was achieved in $100 \%$ of our patients in both the groups which is comparable with that of McNamee et al. (100\%).

In our study in group $\mathrm{R}$, the mean cephalic spread of the sensory level was $\mathrm{T} 4$, mean time for maximum cephalic spread was $4.43 \pm 1.13$ minutes, the mean duration of analgesia at T10 was $177.5 \pm 50.44$ minutes and complete sensory recovery assessed at $\mathrm{S} 1$ level was $329.83 \pm 20.90$ minutes; where as it was T8, 32 minutes, 138 minutes and 354 minutes respectively in earlier study done by Wahedi $e t$ al. which are comparable with our results. Two segment regression from peak sensory level was 84. 92 minutes in our study and is comparable to Gautier et al. but is longer when compared to Mantouvalou et al. who reported a time of $60 \pm 9$ minutes. This difference could be due to the use of a smaller dose $(15 \mathrm{mg})$ of ropivacaine in their study. None of our patients had sensory anaesthesia in the cervical dermatomes which is in contrast to VanKleef et al., Malinovsky et al. and McNamee et al. where reported a cervical sensory levels without affecting upper limb or respiratory function. This may be due to a difference in the characteristics of the populations studied or a difference in the position of the patient during the administration of intrathecal anaesthesia. Whereas in group $\mathrm{L}$, the mean cephalic spread of the sensory level was T6, mean time for maximum cephalic spread was $9.03 \pm 1.99$ minutes, the mean duration of analgesia at T10 was $110.83 \pm 29.36$ minutes and complete sensory recovery assessed at S1 level was $273 \pm 19.10$ minutes. Whereas it was T8, 13.4 $\pm 5.8 \mathrm{~min}$, $226 \pm 26.4 \mathrm{~min}$ in Esmaoglu et al. which are comparable with our study ${ }^{[6,7]}$.

The mean onset time of motor blockade, mean time to achieve maximum blockade (as assessed by Modified Bromage score 3 and duration of motor blockade in group $\mathrm{R}$ were $3.56 \pm 1.13$ minutes, $6.43 \pm 1.13$ minutes and $255.16 \pm$ 29.05 minutes respectively in our study which were comparable with the study by Mantouvalou et al. (31 min, $125 \mathrm{~min}$ and $269 \pm 20 \mathrm{~min}$ ), however Gautier et al. reported $19 \pm 13$ minutes for maximum motor blockade and 189 \pm 44 min for duration of motor blockade. But the achievement of similar motor blockade with a smaller dose of isobaric ropivacaine $(15 \mathrm{mg})$ by Mantouvalou could be because of different definitions of motor study parameters used by them. Complete motor blockade (Modified Bromage 3) was achieved in all of our patients while in McNamee et al. study, all patients achieved a score of at least 1, in contrast to Wahedi et al. who had six patients with incomplete motor blockade.

The mean onset time of motor blockade, mean time to achieve maximum blockade (as assessed by Modified Bromage Score 3) and duration of motor blockade in group L were $7.26 \pm 1.41$ minutes, $12.46 \pm 2.08$ minutes and 202.5 \pm
23.25 minutes respectively in our study which were comparable with the study by Esmaoglu et al. There was statistically no significant difference between the two groups in hemodynamics, oxygen saturation, RSS, duration of surgery and adverse effects ${ }^{[8,9]}$.

In terms of safety, intrathecal ropivacaine produces a high degree of cardiovascular stability with a low incidence of bradycardia, $6.66 \%$ in our study which is comparable with that by Mantouvalu et al. who reported an incidence of $5 \%$ which is in contrast to McNamee et al. The intraoperative hypotension requiring IV ephedrine was $33 \%$ in our study which is comparable to the study by Mantouvalu et al. (25\%) and Mc Namee et al. (24\%). The hypotension was mild and the average requirement of IV ephedrine in 10 patients who had hypotension was $7.85 \mathrm{mg}$. The other common adverse effect was shivering with an incidence of $16.66 \%$, less than that compared to Mantouvalu et al. The reasons could be due to different environmental conditions and methodology of assessment. While none of our patients complained of vomiting, two patients $(6.66 \%)$ had nausea which is comparable to Mantouvalu et al. where $5 \%$ of patients had nausea and no vomiting at all. None of our patients had hypoxia while $10 \%$ of patients had in Mantouvalou et al. ${ }^{[9,10]}$.

In group $\mathrm{L}$ in our study, incidence of bradycardia was $6.66 \%$ which is comparable with that by Esmaoglu et al. who reported an incidence of $10 \%$. The intraoperative hypotension requiring IV ephedrine was $23.33 \%$ in our study, whereas in Esmaoglu et al. incidence of hypotension was zero. The other common adverse effect was shivering with an incidence of $10 \%$. While none of our patients complained of vomiting, four patients $(13.33 \%)$ had nausea. Esmaoglu et al. reported $3.33 \%$ of nausea and vomiting.

Hypotension following SAB is a common complication and also is more hazardous in elderly patients, as they have decreased physiological reserve and compromised blood supply to various vital organs.

Atropine, an antimuscarinic drug, increases the HR and is widely used to treat bradycardia. ${ }^{83}$ The dose-response effect of atropine in patients undergoing SA has not been investigated.

Pruritus is a common complication when intrathecal opioids are used. Liu et al. found that the addition of $20 \mathrm{~g}$ of fentanyl intrathecally led to pruritus in all patients. In our study, only one patient (in group L) complained of pruritus. The administration of intrathecal opioids may provide benefits in augmenting intraoperative anaesthesia, but carries a risk of respiratory depression. In our study all the patients received $\mathrm{O} 2$ by nasal prongs 2-3 liters per minute and maintained $\mathrm{SpO} 2>98 \%$ throughout the study period. Varassi et al. have demonstrated that the subarachnoid administration of $25 \mathrm{~g}$ of fentanyl during spinal anaesthesia in non premedicated elderly men did not alter respiratory rate, end tidal tension of $\mathrm{CO} 2$, minute ventilation, respiratory drive, respiratory timing or the ventilatory response to $\mathrm{CO} 2^{[6,7,9]}$.

The dose of fentanyl used in our study was small, $20 \mathrm{~g}$ and was injected separately after the injection of study drug into subarachnoid space. These reasons probably prevented the cephalad spread and respiratory depression in our study group of patients. Respiratory rate was not documented in our study group.

The onset of motor blockade (3.56 min) is delayed compared to onset of sensory $(1.5 \mathrm{~min})$ blockade in group 
$\mathrm{R}$, whereas in group $\mathrm{L}$ it is $7.26 \mathrm{~min}$ and $4.56 \mathrm{~min}$. But the duration of motor blockade $(255.16 \mathrm{~min}$ in group $\mathrm{R}$, $202.5 \mathrm{~min}$ in group L) is lesser than sensory (329.83 min in group R, 273min in group L), which allows early mobilization of the patients. Hence, intrathecal administration of ropivacaine $(22.5 \mathrm{mg})$ and levobupivacaine (19.5 mg) were well tolerated and provided effective anaesthesia for TURP cases with minimal side effects. Requirement of rescue analgesia was earlier in group $\mathrm{L}$ compared to group $\mathrm{R}$.

\section{Conclusion}

Ropivacaine achieves a longer duration of sensory and motor blockade as compared with $0.5 \%$ isobaric levobupivacaine. With the quality and duration of block achieved with ropivacaine, it can be justified to use it for TURP cases. Furthermore, fentanyl as an adjuvant to both ropivacaine and levobupivacaine enhances the duration of the sensory block. The incidence of rescue analgesia was much earlier in patients who received levobupivacaine with fentanyl.

\section{References}

1. Malhotra V. Transurethral resection of prostate. Anesthesiol Clin North America. 2000; 18:883-97.

2. Sukhani R, Stevens RA. Spinalanesthesia. In: Benzon HT, Raja SN, Borsoo KD, Molloy RE, Strichartz G (eds). Essentials of Pain Medicine and Regional Anaesthesia, NewYork: Churchill Living stone. 1999, 350-57.

3. Wang C, Chakrabarti MK, Whitwam JG. Specific enhancement by fentanyl of the effects of intrathecal bupivacaine or nociceptive afferent but no to sympathetic efferent pathway in dogs. Anesthesiology. 1993; 79:766-73.

4. Labbene I, Lamine K, Gharsallah H, Jebali A, Adhoum A, Ghozzi S et al. Spinal anesthesia for endoscopic urological surgery- low dosevs. Varying doses of hyperbaricbupivacaine. Middle East J Anesthesiol. 2007; 19:369-84.

5. Adhikari D, Gupta SD, Sinha S, Saha A, Bhar SA. clinical trial comparing levobupivacaine, standard and low dose bupivacaine for subarachnoid block to compare the hemodynamic changes as well as effect on early ambulation in patients undergoing transurethral resection of prostate. Int J App Basic Med Sci. 2014; 4(2):44-51.

6. Breebaart MB, Vercauteren MP, Hoffmann VL, Driaensen HA. Urinary bladder scanning after day-case arthroscopy under spinal anesthesia: Comparison between lidocaine, ropivacaine and levobupivacaine. $\mathrm{Br}$ J Anaesth. 2003; 90:309-13.

7. Beers RA, Kane PB, Nsouli I, Krauss D. Doesamidlumbar block level provide adequate anesthesia for transurethral prostatectomy? Can J Anaesth. 1994; 41:807-12.

8. Prajapati J, Parmar H. Low dose bupivacaine and bupivacaine with fentanyl for spinal anesthesia for trans urethral resection of prostate. IAIM. 2015; 2(9):11-19.

9. Mantouvalou M, Ralli S, Arnaoutoglou H, Tziris G, Papadopulos G. Spinal anaesthesia: Comparison of plain ropivacaine, bupivacaine and levobupivacaine for lower abdominal surgery. Acta Anaesth, Belg. 2008; 59:65-71.
10. Liu $\mathrm{S}$ et al. Fentanyl prolongs lidocaine spinal anaesthesia without prolonging recovery. Anesth Analg. 1995; 80:730-4. 